\title{
Allenic Phosphonium Borate Zwitterions via a Transient Phosphonium Allenylidene
}

\author{
Lucas C. Torres, ${ }^{a}$ Roman Dobrovetsky, ${ }^{\text {b }}$ Christopher B. Caputo*a \\ a. Department of Chemistry, York University, 4700 Keele Street, Toronto, Ontario, Canada, M3J1P3 \\ Email: caputo@yorku.ca \\ b. School of Chemistry, Raymond and Beverly Sackler Faculty of Exact Sciences, Tel Aviv University, Tel Aviv 69978, Israel.
}

\begin{abstract}
We describe the synthesis of alkynyl phosphanes of the type $\mathrm{R}_{2} \mathrm{P}-\mathrm{C} \equiv \mathrm{C}-\mathrm{C}\left(\mathrm{OCH}_{3}\right) \mathrm{Ph}_{2},(\mathrm{R}=\mathrm{Ph}, \mathrm{Cy})$ and investigate their transformation to geminally substituted phosphonium borato-allene zwitterions upon their reaction with $\mathrm{B}\left(\mathrm{C}_{6} \mathrm{~F}_{5}\right)_{3}$. The mechanism for this transformation was studied experimentally and by density functional theory computations (DFT), suggesting the intermediacy of an unsaturated 3coordinate phosphonium electrophile akin to a methylene phosphonium cation.

\section{Introduction}

The iminium functional group has been thoroughly studied and is ubiquitous in organic chemistry. ${ }^{1}$ By comparison, the phosphorus containing congener, known as the methylene phosphonium cation, is considerably less explored. Whereas iminium salts typically react as carbon-based electrophiles, ${ }^{2}$ methylene phosphonium cations are fierce phosphorus-centered Lewis acids. ${ }^{3}$ In the late 1980 s, Bertrand and co-workers reported the original preparation of a methylene phosphonium cation of the formulation $\left[\left(i \mathrm{Pr}_{2} \mathrm{~N}\right)_{2} \mathrm{P}=\mathrm{C}\left(\mathrm{SiMe}_{3}\right)_{2}\right]^{+}$by the silylation of a phosphinocarbene precursor (Scheme 1$) \cdot{ }^{3 a} \mathrm{~A}$ synthetic route later reported by Grützmacher and Pritzkow yielded methylene phosphonium salts of the general form $\left[t \mathrm{Bu}_{2} \mathrm{P}=\mathrm{CR}_{2}\right]^{+}$via halogen abstraction from $P$-chloromethylenephosphoranes. ${ }^{4}$ The Erker group recently demonstrated a frustrated Lewis pair (FLP) pathway to methylene phosphonium systems from the reaction of a vinyl substituted phosphane and electrophilic boranes. ${ }^{5}$
\end{abstract}

(a) Bertrand: Addition of TMSOTf to phosphino-carbenes

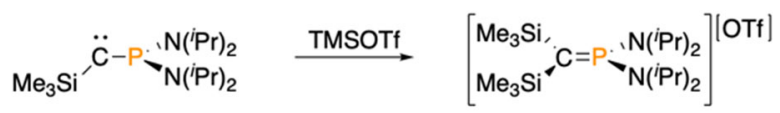

(b) Grützmacher and Pritzkow: Chloride abstraction of $P$-chloromethylenephosphoranes

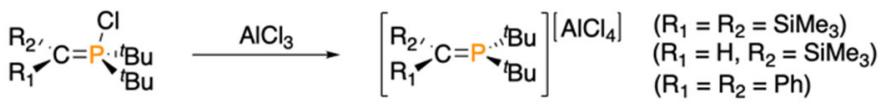

(c) Erker: FLP pathway to methylene phosphonium salts

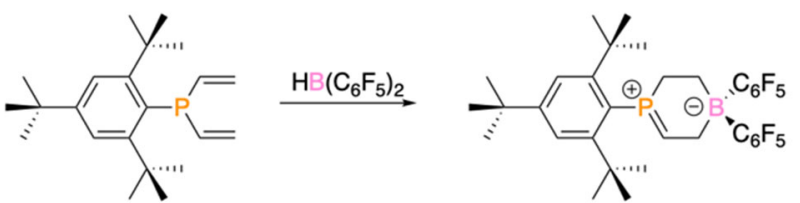

Scheme 1 - Synthesis of early methylene phosphonium systems. 
An alternate bonding description for the methylene phosphonium cation II is the phosphanyl-substituted carbenium ion I (Scheme 2). ${ }^{3 d, 6}$ In a review published over 20 years ago, Bertrand et al. discussed the feasibility of accessing methylene phosphonium salts II by employing precursor phosphanes with abstractable functional groups in the position a to the phosphorus center. ${ }^{\text {ba }}$ The authors noted that a considerable energetic barrier disfavors the formation of planarized phosphonium salts II from pyramidal cationic phosphanes I, evidence of the inferior p-donor properties of phosphorus when compared to nitrogen.

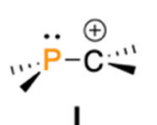

I

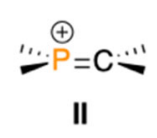

II

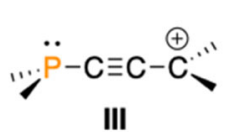

III

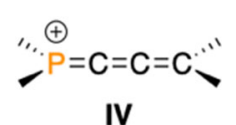

IV

Scheme 2: Structural models for methylene phosphonium cations. Phosphanyl-substituted carbenium ion (I) and a methylene phosphonium cation (II). Alkynyl phosphane linked carbenium ion (III) and a proposed cumulenic methylene phosphonium cation (IV)

Our group is interested in 3-cumulenic analogues of methylene phosphonium species IV, which have yet to be reported. To attempt the synthesis of IV, we envisioned a suitable pathway that first involves the generation of a carbenium ion III, accessed via a heterolytic bond cleavage reaction at the $\mathrm{g}$ carbon of a propargyl- substituted phosphane. ${ }^{7}$ We chose to employ phosphane precursors with a p-electron stabilizing diphenylacetylene substituent, which upon methoxide anion abstraction had the anticipated effect of delocalizing the phosphorus atom lone pair and providing salts akin to IV. We reasoned that the formation of IV over the carbenium ion III could be favourable if the positive charge were delocalized from the main group center over several atoms, possibly counteracting the energetic penalty associated with the planarization of the phosphorus center. This synthetic approach draws direct inspiration from the preparation of cationic allenylidene complexes $\left[\mathrm{L}_{n} \mathrm{M}=\mathrm{C}=\mathrm{C}=\mathrm{CR}_{2}\right][\mathrm{X}]$ accessed from the ionization of neutral acetylide complex. ${ }^{8}$

This communication will detail the synthesis of phosphanes substituted with the $\left(-\mathrm{C} \equiv \mathrm{C}-\mathrm{C}\left(\mathrm{OCH}_{3}\right) \mathrm{Ph}_{2}\right)$ moiety. Abstraction of the $-\mathrm{OCH}_{3}$ by $\mathrm{B}\left(\mathrm{C}_{6} \mathrm{~F}_{5}\right)_{3}$ led to the serendipitous discovery of a reaction that produces allenic phosphonium borate salts in high yield. While we have been unsuccessful in isolating a 3-cumulenic analogue of a methylene phosphonium cation, the isolated zwitterionic products described in this report suggest that the species we initially pursued are likely a transient reaction intermediate. Additionally, we will discuss dichotic results that arise from the ambidentate nature of phosphanes $R_{2} P-C \equiv C-C\left(O C H_{3}\right) P h_{2}$.

\section{Results and Discussion}

Phosphanes $\mathrm{R}_{2} \mathrm{P}-\mathrm{C} \equiv \mathrm{C}-\mathrm{C}\left(\mathrm{OCH}_{3}\right) \mathrm{Ph}_{2}(\mathrm{R}=\mathrm{Ph} \mathbf{1}, \mathrm{Cy} 2, \mathrm{Mes} 3)$ were synthesized in two steps in moderate yields from commercially available 1,1-diphenyl-2-propyn-1-ol (Scheme 3). ${ }^{8,9} \mathbf{1}, \mathbf{2}$, and $\mathbf{3}$ were characterized by multinuclear NMR spectroscopy (see ESI), high-resolution mass spectrometry (HRMS) and the solid-state structure of 1 was determined by single crystal X-ray diffraction (Fig 1, a).

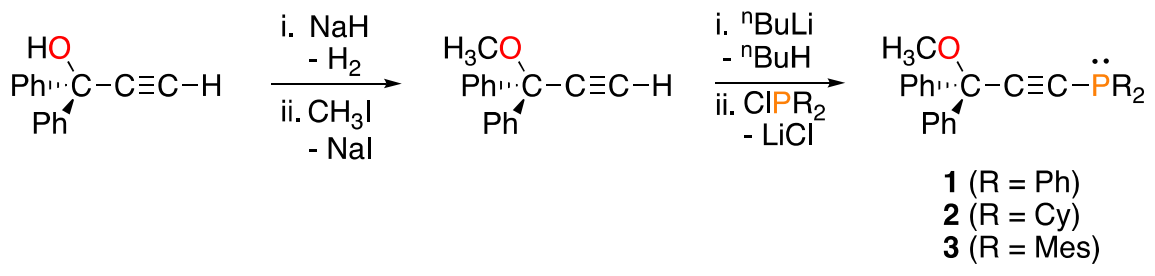

Scheme 3: Synthesis of phosphanes 1-3 
With 1 in hand, we targeted its transformation to the $\left[\mathrm{R}_{2} \mathrm{P}=\mathrm{C}=\mathrm{C}=\mathrm{CR}_{2}\right]^{+}$cation, initially employing trifluoromethylsulfonate (TMSOTf) as a methoxide abstraction reagent. ${ }^{7}$ Addition of a stoichiometric excess of TMSOTf ( 1.5 equiv) to a chloroform- $d$ solution of 1 at $-78^{\circ} \mathrm{C}$, in the absence of light, resulted in a gradual change from colorless to bright yellow. Monitoring the reaction by ${ }^{1} \mathrm{H}$ NMR spectroscopy indicated conversion to a single major product, identified by the generation of a diagnostic doublet resonance at $\delta=4.11 \mathrm{ppm}$ with a small ${ }^{3} \mathrm{JH}_{\mathrm{PH}}$ coupling constant of $12.5 \mathrm{~Hz}$, further confirmed by $2 \mathrm{D}^{1} \mathrm{H}^{3}{ }^{31} \mathrm{P}$ $\{\mathrm{H}\}$ heteronuclear multiple bond coherence experiments. The corresponding ${ }^{31} \mathrm{P}\left\{{ }^{1} \mathrm{H}\right\}$ spectrum displayed a singlet resonance at $\delta=+60.7 \mathrm{ppm}$, shifted to a considerably higher frequency with respect to 1 ( $\Delta \delta$ of $\sim 95 \mathrm{ppm}$ ). Taken together, the spectroscopic features of this reaction mixture were strongly suggestive of methoxide abstraction ( $\mathrm{C}_{\mathrm{g}}-\mathrm{O}$ bond cleavage) of 1 and subsequent alkoxylation at phosphorus producing methoxy-phosphonium of the general form $\left[\mathrm{Ph}_{2} \mathrm{P}\left(\mathrm{OCH}_{3}\right) \mathrm{R}\right]^{+}$(see $\left.\mathrm{ESI}\right) .{ }^{10}$ We encountered difficulties with attempting to isolate or to crystallize the reaction product of $\mathbf{1}$ and TMSOTf to determine its atom connectivity. This prompted us to explore alternative Lewis acidic reagents to facilitate the methoxy group abstraction of phosphane 1.

Along this note, we proceeded to employ $\left[\mathrm{Ph}_{3} \mathrm{C}\right]\left[\mathrm{B}\left(\mathrm{C}_{6} \mathrm{~F}_{5}\right)_{4}\right]$ and $\mathrm{B}\left(\mathrm{C}_{6} \mathrm{~F}_{5}\right)_{3}$ as potential $-\mathrm{OCH}_{3}$ abstracting reagent. Addition of an equimolar amount of $\left[\mathrm{Ph}_{3} \mathrm{C}\right]\left[\mathrm{B}\left(\mathrm{C}_{6} \mathrm{~F}_{5}\right)_{4}\right]$ to $\mathbf{1}$ gave the Lewis adduct [1 $\left.\mathrm{CPh}_{3}\right]\left[\mathrm{B}\left(\mathrm{C}_{6} \mathrm{~F}_{5}\right)_{4}\right]$ as determined by ${ }^{31} \mathrm{P},{ }^{19} \mathrm{~F},{ }^{13} \mathrm{C}$ and ${ }^{11} \mathrm{~B}$ spectroscopic methods (Scheme 4). ${ }^{11}$ Formation of the trityl phosphonium borate $\left[1 \mathrm{CPh}_{3}\right]\left[\mathrm{B}\left(\mathrm{C}_{6} \mathrm{~F}_{5}\right)_{4}\right]$ demonstrates Lewis adduct formation at the phosphorus lone pair of 1 , while the $\mathrm{C}_{\mathrm{g}}-\mathrm{O}$ bond remains intact. Combining 1 with a stoichiometric quantity of $\mathrm{B}\left(\mathrm{C}_{6} \mathrm{~F}_{5}\right)_{3}$ at room temperature in benzene, resulted in no obvious colour change upon dissolution. After 3 hours, analysis of a reaction aliquot by ${ }^{31} \mathrm{P}\left\{{ }^{1} \mathrm{H}\right\}$ NMR spectroscopy indicated complete consumption of 1 and the formation of a major species in solution (ca. 94\%), which displayed a broadened singlet centered at $\delta=$ $3.71 \mathrm{ppm}$. The corresponding ${ }^{1} \mathrm{H}$ NMR spectrum retained the diagnostic singlet resonance of the $-\mathrm{OCH}_{3}$ moiety in $\mathbf{1}$. Taken together, we likened the product to be the phosphane Lewis adduct $1-B\left(C_{6} F_{5}\right)_{3}$. However, heating this mixture to $60^{\circ} \mathrm{C}$ resulted in quantitative conversion to a new product 4 , evidenced by the generation of a ${ }^{31} \mathrm{P}\left\{{ }^{1} \mathrm{H}\right\}$ NMR resonance at $\mathrm{d}=67.0 \mathrm{ppm}$. The corresponding ${ }^{1} \mathrm{H}$ NMR spectrum showed a doublet resonance at $d=2.93 \mathrm{ppm}\left({ }^{3} \mathrm{JPH}_{\mathrm{PH}} 11.4 \mathrm{~Hz}\right)$, which collapsed to a singlet upon ${ }^{31} \mathrm{P}$ decoupling. In the ${ }^{11} \mathrm{~B}\left\{{ }^{1} \mathrm{H}\right\}$ NMR spectrum, a sharp signal was observed at $\mathrm{d}=-13.6 \mathrm{ppm}$, and the ${ }^{19} \mathrm{~F} N \mathrm{NR}$ spectrum showed a set of signals at $d=-129.6 \mathrm{ppm}(o-\mathrm{F}),-159.7 \mathrm{ppm}(p-\mathrm{F})$ and - $165.1 \mathrm{ppm}(m-\mathrm{F})$, supporting the structure of 4 as a zwitterion containing a phosphonium cation and tetracoordinate boron center. ${ }^{12}$ The $\mathrm{C}\left\{{ }^{1} \mathrm{H}\right\}$ NMR spectrum showed a resonance at $\mathrm{d}=+214 \mathrm{ppm}$ diagnostic of an sp-hybridized allenic carbon atom. Upon work up, 4 was isolated as an analytically pure yellow solid in $67 \%$ yield. Recrystallization from a layered solution of $\mathrm{CH}_{2} \mathrm{Cl}_{2}$ and pentane afforded X-ray crystallographic quality single crystals of $\mathbf{4}$ confirming its structure (Scheme 4). The allene fragment of $\mathbf{4}$ is almost completely linear (C1-C2-C3 of ca. $\left.176.0(2)^{\circ}\right)$. The P1-C1 bond distance of 4 is $1.779(2) \AA$, longer with respect to the P1-C1 of $11.762(2) \AA$. Elongation of the C1-C2 bond is observed upon salt formation from 1.210 (3) $\AA$ to $1.311(2) \AA$, in agreement with an overall decreased bond order from 3 (alkyne) to 2 (alkene). Contraction of the C2-C3 bond was observed from 1.476(3) $\AA$ in 1 to 1.317(2) $\AA$ in 4 . The bond angles around C1 and C3 sum to $359.0(3)^{\circ}$ and $360(3)^{\circ}$ respectively. Additionally, the substituents on C1 and C3 lie within orthogonal planes, confirming an allene type structure with extended tetrahedral geometry. 


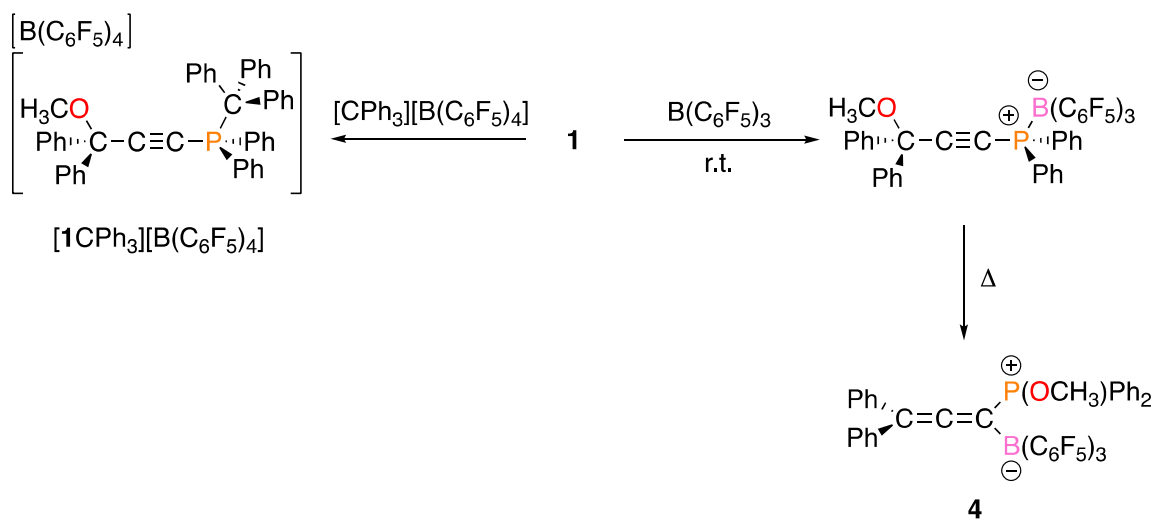

Scheme 4: Synthesis of salt $\left[1 \mathrm{CPh}_{3}\right]\left[\mathrm{B}\left(\mathrm{C}_{6} \mathrm{~F}_{5}\right)_{4}\right]$ and zwitterion 4.

a.

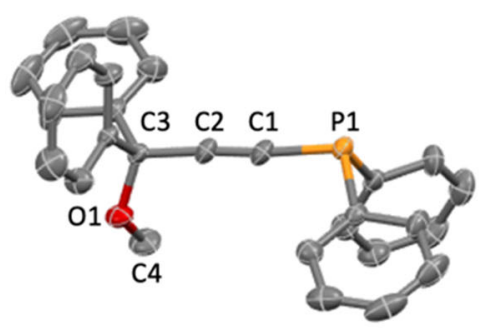

b.

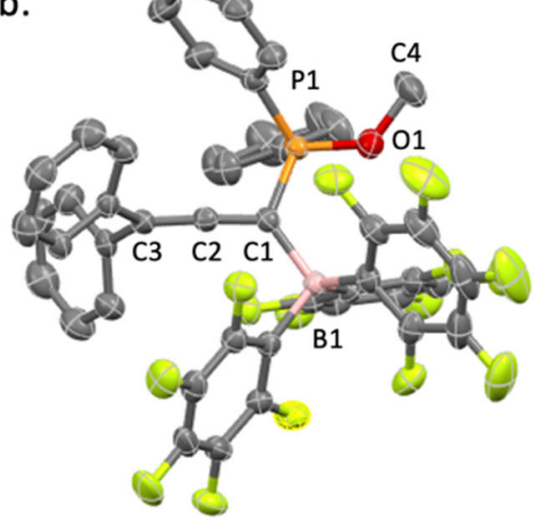

Figure 1: Solid state molecular structure of 1 (left) and 4 (right). All hydrogens atoms are omitted for clarity. Thermal ellipsoids are drawn at $50 \%$ probability.

The analogous product 5 was prepared from 2 and $B\left(\mathrm{C}_{6} \mathrm{~F}_{5}\right)_{3}$ in $63 \%$ yield as an orange solid. Notably, this reaction occurs relatively quickly when compared to the reaction of 1 and $B\left(C_{6} F_{5}\right)_{3}$, and even proceeds to completion in the absence of an external heat source $\left(12 \mathrm{~h}, 25^{\circ} \mathrm{C}\right)$. We attribute this difference in reactivity to the increased steric bulk of $\mathbf{2}$ imparted by larger cyclohexyl substituents, which may minimize competing phosphane-borane interactions. The spectroscopic features of $\mathbf{5}$ are virtually identical to $\mathbf{4}$ with diagnostic NMR features at $\delta_{H}=2.71(\mathrm{~d}), \delta_{\mathrm{B}}=-13.4, \delta_{\mathrm{P}}=+82.8, \delta_{\mathrm{C}}=+212.5$. In no circumstance did we observe any evidence of 1,1 carboboration products arising from reactions of either 1 or 2 with $B\left(C_{6} F_{5}\right)_{3}{ }^{13}$

The unprecedented rearrangement reaction leading to products 4 and 5 from their respective alkynyl phosphanes 1 and $\mathbf{2}$ was encouraging evidence for our hypothesized approach to $\left[R_{2} P=C=C=C R_{2}\right]^{+}$cations. We suspect the intermediacy of an unsaturated 3-coordinate phosphonium electrophile may explain the connectivity of $\mathbf{4}$ and $\mathbf{5}$. In an attempt to isolate this intermediate, we employed the bulkier substrate $\mathbf{3}$, anticipating that mesityl substituents may provide a greater measure of kinetic stabilization. While mixing 3 with $\mathrm{B}\left(\mathrm{C}_{6} \mathrm{~F}_{5}\right)_{3}$ in benzene at room temperature gave an intractable mixture of reaction products, the same reaction in pentane led to the instantaneous formation of a light green precipitate. Isolating and dissolving this precipitate in benzene- $d_{6}$ revealed the formation of a single new product, evidenced by a pair of doublets in the ${ }^{31} \mathrm{P}\left\{{ }^{1} \mathrm{H}\right\}$ NMR spectrum at $\mathrm{d}=-5.36$ and $-18.72 \mathrm{ppm}$, sharing identical coupling constants $\left({ }^{1} J_{\mathrm{PP}}=211 \mathrm{~Hz}\right)$, and integrating in a ratio of $1: 1$. The large coupling constant and doublet splitting pattern 
indicated a new species with two chemically distinct phosphorus environments connected through a single bond. $A{ }^{11} B$ NMR signal at $d=-1.68 \mathrm{ppm}$ suggested the formation of the tetracoordinate borate counter anion $\left[\mathrm{H}_{3} \mathrm{CO}-\mathrm{B}\left(\mathrm{C}_{6} \mathrm{~F}_{5}\right)_{3}\right]^{-}$. Notable features of the ${ }^{1} \mathrm{H}$ NMR spectrum include two resonances for the $-\mathrm{OCH}_{3}$ functionality, one singlet at $d=2.75 \mathrm{ppm}$, and a second broad singlet at $d=3.55 \mathrm{ppm}$, which integrate equally. Based on the above spectroscopic features, we have tentatively assigned this product to be the cationic phosphine phosphonium adduct 6 (as depicted in Scheme 5). Compound 6 decomposes slowly in solution ( $90-95 \%$ remaining after 2 days) and all attempts to grow single crystals for X-ray diffraction have been unsuccessful to date.

Concerning the mechanism for the formation of $\mathbf{4}$ and $\mathbf{5}$, we believe that the reaction process is initiated by a borane-mediated $\mathrm{C}_{\mathrm{g}}-\mathrm{OCH}_{3}$ bond cleavage event to generate an ion pair of a tri-coordinate phosphonium cation and the borate anion $\left[\mathrm{H}_{3} \mathrm{CO}-\mathrm{B}\left(\mathrm{C}_{6} \mathrm{~F}_{5}\right)_{3}\right]^{-}$(Depicted as Int2 in Figure 2). The methoxide moiety from the anion $\left[\mathrm{H}_{3} \mathrm{CO}-\mathrm{B}\left(\mathrm{C}_{6} \mathrm{~F}_{5}\right)_{3}\right]^{-}$is delivered to the Lewis acidic phosphonium cation, to give phosphacumulene ylides (Int4). Products $\mathbf{4}$ and $\mathbf{5}$ are Lewis adducts of the aforementioned ylides and $B\left(C_{6} F_{5}\right)_{3}$, structurally resembling a $P / B$ inner salt prepared by the Krempner group from Bestmann's ylide $\left(\mathrm{Ph}_{3} \mathrm{PCCO}\right) .{ }^{12}$ Compounds $\mathbf{1}$ and $\mathbf{2}$ can presumably form classical $\mathrm{P}-\mathrm{B}$ Lewis adducts with $\mathrm{B}\left(\mathrm{C}_{6} \mathrm{~F}_{5}\right)_{3}(\mathrm{Scheme}$ 4), a process that competes with $\mathrm{C}_{\mathrm{g}}-\mathrm{OCH}_{3}$ abstraction. Lastly, the generation of 6 from $\mathbf{3}$ and $\mathrm{B}\left(\mathrm{C}_{6} \mathrm{~F}_{5}\right)_{3}$ in pentane solution suggests cations like Int2 may be involved in the reaction cascade that yields allenes 4 and $\mathbf{5}$ from their respective phosphanes.

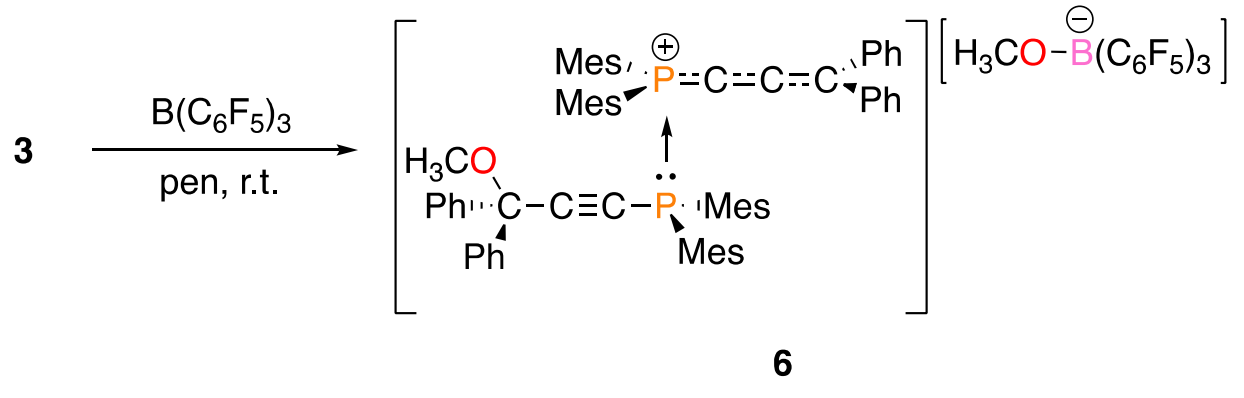

Scheme 5: Formation of adduct 6 from 3 and $B\left(C_{6} F_{5}\right)_{3}$

To support the proposed mechanism for the formation of zwitterions 4 and 5, density functional theory (DFT) computations at the BP86-D3/def2SVP level of theory in the gas phase for the reaction involving the 1 and $B\left(C_{6} F_{5}\right)_{3}$ were performed. ${ }^{14,15}$ As a result, we found that the first step of this transformation involves coordination of the ether moiety in 1 to $B\left(\mathrm{C}_{6} \mathrm{~F}_{5}\right)_{3}$, providing the $\mathrm{B}-\mathrm{O}$ Lewis adduct Int1. This step is slightly exergonic $\left(\Delta G=-5.5 \mathrm{kcal} \mathrm{mol}^{-1}\right)$ and highly exothermic $\left(\Delta H=-23.5 \mathrm{kcal} \mathrm{mol}^{-1}\right)$. Heterolytic cleavage of the $\mathrm{C}-\mathrm{O}$ bond leading to salt Int2 is both exergonic $(\Delta G=-13.59)$ and exothermic $\left(\Delta H=-7.44 \mathrm{kcal} \mathrm{mol}^{-1}\right)$. The structural parameters of Int2 suggest that the structure has some delocalization across the $\mathrm{P}-\mathrm{C}-\mathrm{C}-\mathrm{C}$ vector with a shortened P-C bond length of $1.732 \AA$, compared to 1 (1.762(2) $\AA$ ). Furthermore, the CC triple-bond length increased from 1.198(3) $\AA$ in 1 to $1.248 \AA$ in Int2, with a related bond contraction between $\mathrm{C} 2$ and C3 (Figure 1) from 1.481(3) $\AA$ in 1 to $1.388 \AA$ in Int2. Compared to the methylene phosphonium cation reported by Grützmacher and co-workers, $\left[\mathrm{tBu}_{2} \mathrm{P}=\mathrm{CPh}_{2}\right]^{+}$which has a $\mathrm{P}=\mathrm{C}$ bond length of $1.683 \AA$, suggests that while delocalization is occurring in our system, we do not have complete $\mathrm{P}-\mathrm{C}$ double bond formation and it is best described as a hybrid of structures III and IV in Scheme 1. Frontier orbital analysis indicate that both the HOMO and LUMO are found across the P-C-C-C fragment (ESI Figure 9) supporting the 
observed bond parameters of Int2. From Int2, the P-O adduct formation producing intermediate Int3 is barrierless. $\mathrm{P}-\mathrm{O}$ bond formation and $\mathrm{B}-\mathrm{O}$ bond breakage leading to phosphacumulene ylide Int4 is an endergonic and endothermic reaction $\left(\Delta G=5.84\right.$ and $\left.\Delta H=7.44 \mathrm{kcal} \mathrm{mol}^{-1}\right)$ and is the rate determining step with $\Delta G^{\#}$ of $8.34 \mathrm{kcal} \mathrm{mol}^{-1}$. The last step of this process, the association of Int4 and $\mathrm{B}\left(\mathrm{C}_{6} \mathrm{~F}_{5}\right)_{3}$ to give 4

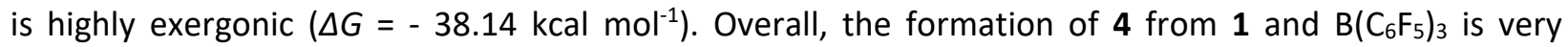
exergonic and exothermic $\left(\Delta G=-46.48\right.$ and $\left.\Delta H=-65.12 \mathrm{kcal} \mathrm{mol}^{-1}\right)$. Despite this, in our experimentation, the reaction was very slow in the absence of heating. It is reasonable to assume that this is a consequence of the formation of $\mathbf{A} \mathbf{1}$ which is a highly exergonic $\left(\Delta G=-19.2 \mathrm{kcal} \mathrm{mol}^{-1}\right)$ and thus inhibits the reaction from proceeding. These calculations support our initial suggestion that this transformation possibly proceeds via an unsaturated tricoordinate P-centered electrophilic intermediate. However, the highly reactive nature of Int2 has made the isolation of Int2 impossible due to consequent reaction of this intermediate with the rather strong B-O bond ultimately leading to product 4.

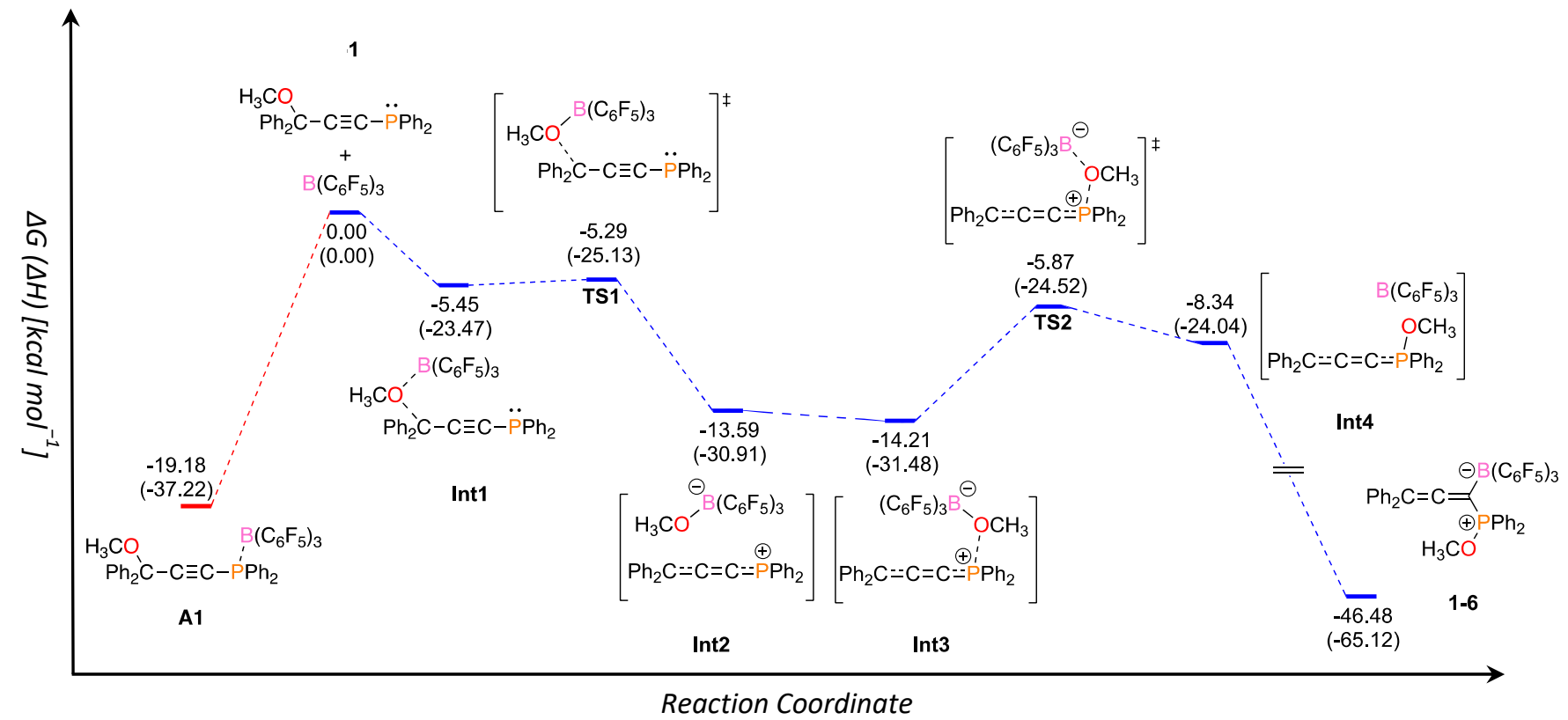

Figure 2: Potential energy surface calculated for a possible reaction mechanism for the formation 4. Energies are reported relative to the starting materials. Gibbs free energies and enthalpies (in parenthesis) given in $\mathrm{kcal} \mathrm{mol}^{-1}$.

\section{Conclusion}

In conclusion, we have prepared the geminal phosphonium borate zwitterions $\mathbf{4}$ and $\mathbf{5}$ through $\mathrm{B}\left(\mathrm{C}_{6} \mathrm{~F}_{5}\right)_{3}$ mediated methoxide abstraction of the alkynyl phosphanes 1 and 2, respectively. We are currently exploring the potential applicability of this transformation towards the isolation of Lewis-base free phosphorus/carbon-based tricoordinate salts $\left[\mathbf{R}_{\mathbf{2}} \mathbf{P}=\mathbf{C}=\mathbf{C}=\mathbf{C R}_{\mathbf{2}}\right]^{+}$, as well its general utility for synthesizing phosphorus/boron materials.

The Natural Sciences and Engineering Research Council of Canada (NSERC) and Canada Research Chairs Program is thanked for their support of C.B. Caputo. J. N. Bentley is sincerely thanked for X-ray diffraction data collection. A.M. Borys and S. Manhas are thanked for their mentorship and for helpful discussions. 
Lastly, L.C. Torres acknowledges the support provided by the Province of Ontario through the Ontario Graduate Scholarship.

\section{Conflicts of Interest}

The authors declare no conflicts of interest.

\section{Notes and References}

1 M. Arend, B. Westermann and N. Risch, Angew. Chem. Int. Ed. 1998, 37, 1044-1070.

2 A. Erkkilä, I. Majander and P. M. Pihko, Chem. Rev. 2007, 107, 5416-5470.

3 For reactivity of methylene phosphonium salts see e.g. (a) A. Igau, A. Bacereido, H. Grützmacher, H. Pritzkow and G. Bertrand, J. Am. Chem. Soc. 1989, 111, 6853. (b) U. Heim, H. Pritzkow, U. Fleischer and H. Grützmacher, Angew. Chem. Int. Ed. 1993, 32, 1359. (c) U. Heim, H. Pritzkow, U. Fleischer, H. Grützmacher, M. Sanchez, R. Réau and G. Bertrand, Chem. Eur. J. 1996, 2, 68. (d) J. Thomaier, G. Alcaraz, H. Grützmacher, H. Hillebrecht, C. Marchand and U. Heim, J. Organomet. Chem. 1997, 535, 91.

4 (a) H. Grützmacher and H. Pritzkow, Angew. Chem. Int. Ed. 1992, 31, 99. (b) U. Heim, H. Pritzkow, H. Schönberg and H. Grützmacher, J. Chem. Soc., Chem. Commun. 1993, 673-674.

5 (a) Y. Hasegawa, G. Kehr, S. Ehrlich, S. Grimme, C. G. Daniliuc and G. Erker, Chem. Sci. 2014, 5, 797803. (b) Y. Hasegawa, C. G. Daniliuc, G. Kehr and G. Erker, Angew. Chem. Int. Ed. 2014, 53, 1216812171.

6 Heteroatom-stabilized carbenium ions: (a) O. Guerret and G. Bertrand, Acc. Chem. Res. 1997, 30, 486-493. (b) H. Grützmacher and C. M. Marchand, Coord. Chem. Rev. 1997, 163, 287. (c) R. C. Fischer and P. P. Power, Chem. Rev. 2010, 110, 3877.

7 E. D. Litle, L. C. Wilkins, and F. P. Gabbaï, Chem. Sci. 2021, 12, 3929.

8 (a) N. Kim and R. A. Widenhoefer, Angew. Chem. Int. Ed. 1992, 2018, 57, 4722-4726. (b) F. Strinitz, J. Tucher, J.A. Januszewski, A. R. Waterloo, P. Stegner, S. Förtsch, E. Hübner, R. R. Tykwinski, and N. Burzlaff, Organometallics 2014, 33, 5129-5144.

9 O. Ekkert, R. Fröhlich, G. Kehr and G. Erker, J. Am. Chem. Soc. 2011, 133, 4610-4616.

10 R. Garcia-Rodriguez and H. Liu, J. Am. Chem. Soc. 2011, 134, 1400-1403.

11 For phosphine trityl adducts see, e.g. (a) J. B. Lambert and J.-H. So, J. Org. Chem. 1991, 56, 59605962. (b) L. Cabrera, G.C. Welch, J. D. Masuda, P. Wei and D. W. Stephan. Inorg. Chim. Acta 2006, 359, 3066-3071.

12 See for comparison: A. Brar, D. K. Unruh, A. J. Aquino and C. Krempner, Chem. Commun. 2019, 55, 3513-3516.

13 See examples of 1-1 carboboration of alkynyl phosphanes: (a) O. Ekkert, O. Tuschewitzki, C. G. Daniliuc, G. Kehr and G. Erker, Chem. Commun. 2013, 49, 6992-6994. (b) O. Ekkert, R. Fröhlich, G. Kehr and G. Erker, Chem. Commun. 2011, 47, 4610-4616. 
14 (a) Q. S. Li, J. Zhang and S. Zhang, Chem. Phys. Lett. 2005, 404, 100-106. (b) S. Grimme, J. Antony, S. Ehrlich and H. Krieg, J. Chem. Phys. 2010, 132, 154104.

15 F. Weigend and R. Ahlrichs, Phys. Chem. Chem. Phys., 2005, 7, 3297-3305 